\title{
Development and Formulation of the Experimental Dentifrice Based on Passiflora mollissima (Tumbo) with and without Fluoride Anion: Antibacterial Activity on Seven Antimicrobial Strains
}

\author{
Frank Mayta-Tovalino $\mathbb{D}^{1},{ }^{1,2,3}$ Eloy Gamboa, ${ }^{1,2}$ Richard Sánchez, ${ }^{1,3}$ Jorge Rios, ${ }^{1}$ \\ Ramín Medina, ${ }^{4}$ Martín García, ${ }^{4}$ and Jhonn Asencios ${ }^{4}$ \\ ${ }^{1}$ Professor of Stomatology School, Universidad Privada San Juan Bautista, Lima, Peru \\ ${ }^{2}$ Department of Basic Sciences, Faculty of Health Sciences, Universidad Privada San Juan Bautista, Lima, Peru \\ ${ }^{3}$ Department of Chemistry, Faculty of Health Sciences, Universidad Privada San Juan Bautista, Lima, Peru \\ ${ }^{4}$ Stomatology School, Universidad Privada San Juan Bautista, Lima, Peru
}

Correspondence should be addressed to Frank Mayta-Tovalino; estadistico2.0@gmail.com

Received 15 February 2019; Revised 14 May 2019; Accepted 21 May 2019; Published 13 June 2019

Academic Editor: Alessandro Leite Cavalcanti

Copyright ( 2019 Frank Mayta-Tovalino et al. This is an open access article distributed under the Creative Commons Attribution License, which permits unrestricted use, distribution, and reproduction in any medium, provided the original work is properly cited.

\begin{abstract}
Objectives. To develop and formulate a new experimental dentifrice with and without fluoride based on the peel and the fruit of the Passiflora mollissima (tumbo) and also to evaluate its antimicrobial activity against seven bacterial strains. Methods. The sample was calculated using the mean comparison formula, obtaining wells $(n=12)$ for each of the strains evaluated: $S$. mutans, E. faecalis, Actinomyces, Lactobacillus, C. albicans, S. sanguinis, and S. oralis. The antibacterial activity of the dentifrice was evaluated by the direct contact technique. Results. It was found that the highest antimicrobial activity was only present in pulp-based dentifrices against strains of $S$. mutans $21.0 \pm 1.8$, E. faecalis $16.3 \pm 3.9$, Actinomyces $22.1 \pm 1.3$, and Lactobacillus $21.0 \pm 1.3$. However, in comparison with other strains such as C. albicans, S. sanguinis, and S. oralis, the peel-based dendrifrice of Passiflora mollissima obtained the highest antimicrobial activity. Conclusion. The experimental dentifrice based on Passiflora mollissima had an antibacterial effect against the seven microbial strains during the first 24 and 48 hours.
\end{abstract}

\section{Introduction}

Toothpastes have been in use for many decades [1], and they are one of the main irreplaceable hygiene products in oral health. The design of toothpaste formulations began in China and India, during 300-500 BC. During that period, crushed bone, powdered egg shell, and clam shells were used as abrasives for oral cleansing. Modern formulations of toothpaste date back to the 19th century; subsequently, soaps and other abrasives were incorporated into these formulations. After 1945, several advances in the formulation of different detergents had been initiated, and sodium lauryl sulfate was used as an emulsifying agent $[2,3]$. However, in recent years, the focus has shifted towards the release of active ingredients from natural resources immersed in the formulation to prevent and/or treat certain oral diseases [4].

Oral hygiene is controlled by toothpaste with the aim of reducing oral bacterial flora. Biofilm [1] is a layer that is usually formed on the surface of a tooth. So, some previous studies have shown that dental plaque can be controlled by the physical elimination of bacteria and the use of antimicrobial toothpastes and mouth rinses. There are several types of bacteria in the mouth; some are useful and others are harmful such as Neisseria, Staphylococcus, S. pneumoniae, and Porphyromonas gingivalis $[5,6]$. 
On the contrary, the consumption of tropical fruits by the world population is increasing as their nutritional value is better known. These fruits in which the presence of exotic characteristics and nutrients helps treating certain diseases offer an opportunity for local farmers to access special markets. Apart from the nutritional and therapeutic value, most of these native plants have considerable amounts of micronutrients, such as minerals, fibers, vitamins, and secondary phenolic compounds, that can be used in dentistry [7-9].

Tumbo is a plant that belongs to the family Passifloraceae, which grows in Andean areas of South America approximately between 2000 and 3600 meters above the sea level. This native fruit is a rich source of vitamin C, which gives it an excellent antioxidant capacity [9]. It is a source of calcium, iron, phosphorus, potassium, and fiber. In addition, some research on its leaf, skin, and the edible part of this fruit revealed that it is rich in natural phenolic antioxidants. For example, in this sense, some authors have discovered that the antioxidant activity of Passiflora mollissima fruit can be compared with that of ascorbic acid, which is the main source of natural antioxidant used in the food industries. On the contrary, its health-promoting effect can be attributed to its polyphenols, especially flavonoids and carotenoids, which have been strongly associated with antioxidant capacity, in addition to presenting certain antimicrobial properties [10-13].

Therefore, the objective of this research was to develop and formulate an experimental dentifrice based on the peel and fruit of Passiflora mollissima (tumbo) and to evaluate its antimicrobial effectiveness against seven strains of the oral cavity.

\section{Materials and Methods}

2.1. Sample Size. The unit of analysis was formed by a well created on the agar in which the experimental dentifrice based on the fruit and peel of Passiflora mollissima (tumbo) was introduced, confronted in the Petri dishes, and inoculated with the cultivated strains of S. mutans, E. faecalis, Actinomyces, Lactobacillus, C. albicans, S. sanguinis, and S. oralis. The sample size was calculated by the comparison formula using the Stata ${ }^{\circledR}$ software version 12.0, with an alpha of 0.05 and a power of test of 0.8 , obtaining wells $(n=12)$ for each group evaluated. Finally, the following groups were considered based on the peel and pulp of Passiflora mollissima:

Group 1: Petri dishes sown with strains of Streptococcus mutans (ATCC ${ }^{\circledR}$ 25175).

Group 2: Petri dishes sown with strains of Enterococcus faecalis (ATCC ${ }^{\circledR}$ 29212).

Group 3: Petri dishes sown with strains of Actinomyces (ATCC ${ }^{\circledR}$ 12104).

Group 4: Petri dishes sown with strains of Lactobacillus (ATCC ${ }^{\circledR}$ 11146).

Group 5: Petri dishes sown with strains of Candida albicans (ATCC ${ }^{\circledR}$ 10231).
Group 6: Petri dishes sown with strains of Streptococcus sanguinis (ATCC ${ }^{\circledR}$ 10556).

Group 7: Petri dishes sown with strains of Streptococcus oralis (ATCC ${ }^{\circledR}$ 6249).

Group 8: Controls of commercial toothpastes (Dento Herbal ${ }^{\circledR}, \quad$ Colgate $\operatorname{Herbal}^{\circledR}$, Kolynos $\mathrm{Herbal}^{\circledR}$, Sensodyne ${ }^{\circledR}$, and Parodontax ${ }^{\circledR}$ ).

2.2. Herbal Classification. To certify the phenotype, the plant was analyzed by the Herbarium of the Natural History Museum of the Universidad Nacional Mayor de San Marcos (UNMSM) with code No. 098-USM-2017, obtaining the following classification:

Division: Magnoliophyta
Subclass: Magnoliopsida
Order: Violales
Family: Passifloraceae
Genus: Passiflora
Species: Passiflora tripartita var. mollissima (Kunth)
Holm-Niels and P. Jorg.

2.3. Preparation of Tumbo Methanolic Extract. Passiflora mollissima was obtained from the city of Huaraz, Peru, located at latitude $-9.5277900^{\circ}$ and longitude $-77.5277800^{\circ}$. To obtain the methanol extract from the pulp, $2000 \mathrm{ml}$ of methanol $\left(\mathrm{CH}_{3} \mathrm{OH}\right)$ Merck was used, which was mixed with $2 \mathrm{~kg}$ of the "tumbo" pulp. The peel of the fruit, once washed thoroughly with distilled water, was liquefied, and a uniform mass of $1100 \mathrm{~g}$ was obtained. Subsequently, the solvent medium, $1000 \mathrm{ml}$ of methanol, was added. Both the pulp and peel mixtures were allowed to stand for a period of 10 days, shaken periodically three times a day, and subjected to multiple filtering processes with the Whatman filter paper. Subsequently, the extracts were placed in a "Memmert" laboratory stove (model EU 500) for a period of 8 days at a constant temperature of $45^{\circ} \mathrm{C}$, with the intention of volatilizing ethanol and obtaining highly pure extracts $[14,15]$.

2.4. Sowing Technique. The biotube containing the lyophilized strain of the bacteria belonging to the genus Streptococcus was initially taken. This biotube is subjected to a slight pressure at its upper end with the intention of breaking an inner bulb which releases the bacterial suspension in an internal aqueous agent so that a solution containing the strain itself was obtained ready to grow. With the help of a sterile swab, a sample of this solution containing the bacterial strain was taken, to be later taken to the Petri dishes of dimensions $150 \times 30 \mathrm{~mm}$ containing the culture media TSA agar and nutritive agar; in both cases, they are cultivated with the method of sowing on grass. Once the plantings were completed, they were plated and labeled, and finally, all the cultivated plates were place in a laboratory Auto-Flow UN4950 incubator at a temperature of $37^{\circ} \mathrm{C}$ for a period of 24 hours. Finally, the inhibition halos produced by the different evaluated groups were measured by the technique 
of direct contact in the well, measuring the zones of inhibition in millimeters with a digital Vernier caliper $[14,15]$.

\subsection{Preparation of Tumbo Dentifrice (TD). Precipitated} calcium carbonate was used and mixed in $50 \mathrm{ml}$ of distilled or deionized water with continuous stirring, and then the additives of tetrasodium pyrophosphate, AEROSIL (hydrophilic pyrogenic silica) were added: Colloidal silicon dioxide USP, NIPAGIN (methylparaben sodium) or methyl parahydroxybenzoate, saccharin sodium powder, and menthol crystals were also added. The stirring was maintained, and the glycerin was added to achieve a homogeneous mixture; finally, the xanthan gum, titanium dioxide (dye), sodium lauryl sulfate (SLE), and methanol extract of dilute Passiflora mollissima pulp (10 g in $10 \mathrm{~mL}$ of distilled water) were added $[4,6]$. The same procedure was carried out for the dentifrice based on "tumbo" peel in both versions; the only difference was that in one formulation, fluoride was added, and in another, it was not (Table 1).

2.6. Declaration of Ethics. Authorization was obtained from the Ethics Committee of the San Juan Bautista Private University (Code CEPB-FCS0007) for the execution of the research project because it forms part of a research line of the university. Because it is an experimental in vitro research, no risks are anticipated, and all the Petri dishes inoculated with the different strains were duly sterilized and discarded under the biosecurity protocols of the laboratory.

2.7. Statistical Analysis. For the descriptive analysis of the quantitative variable antimicrobial effect, we proceeded to obtain the descriptive statistics (mean and standard deviation) of all the groups evaluated. Then, the assumption of normality and homogeneity of the variances was determined by the Shapiro-Wilk and Levene tests, respectively. Finally, for the bivariate analysis, the Student $t$-test, the MannWhitney $U$ test, and the Kruskal-Wallis test were used. A level of significance of $p<0.05$ was established, and the complete analysis was carried out using the Stata 12.0 software.

\section{Results}

3.1. Antimicrobial Activity of Dentifrice of Passiflora mollissima (Tumbo) without Fluoride Anion. Table 2 shows that when comparing the antimicrobial effects of the experimental dentifrice of the pulp and peel of the Passiflora mollissima, it was evidenced that the pulp of the fruit had the highest activity at 24 or 48 hours against the strains of $S$. mutans $(20.0 \pm 2.1 \mathrm{~mm})$, E. faecalis $(15.5 \pm 1.1 \mathrm{~mm})$, Actinomyces $(23.6 \pm 4.4 \mathrm{~mm})$, Lactobacillus $(20.8 \pm 0.6)$, and $C$. albicans $(24.7 \pm 1.3 \mathrm{~mm})$ of inhibition halos. However, toothpaste based on "tumbo" peel only had a greater effectiveness against strains of $S$. sanguinis $(15.9 \pm 0.4 \mathrm{~mm})$ and $S$. oralis $(16.5 \pm 0.4 \mathrm{~mm})$. Despite these differences, both pulp- and peel-based toothpastes presented optimal antimicrobial effects against the seven oral strains evaluated.
Finally, when assessing normality, only strains of E. faecalis, Lactobacillus, C. albicans, and S. sanguinis showed normal distribution $(p>0.05)$.

3.2. Antimicrobial Activity of Dentifrice of Passiflora mollissima (Tumbo) with Fluoride Anion. Table 3 shows that when comparing the antimicrobial activity, pulp-based toothpaste with fluoride anion added in the formulation had the highest activity against strains $S$. mutans $(21.0 \pm 1.8 \mathrm{~mm})$, E. faecalis $(16.3 \pm 3.9 \mathrm{~mm})$, Actinomyces $(22.1 \pm 1.3 \mathrm{~mm})$, Lactobacillus $(21.0 \pm 0.3 \mathrm{~mm})$, and C. albicans (21.2 \pm 1.9$)$ millimeters of inhibition halos; even this increase in its effectiveness is slightly greater than the activity described in the previous table, so there would apparently be a synergism that generates the fluoride anion in the antimicrobial activity. On the contrary, peel-based toothpaste with the added fluoride ion added only a higher activity against $S$. sanguinis $(15.5 \pm 0.5 \mathrm{~mm})$ and S. oralis $(17.0 \pm 0.4 \mathrm{~mm})$ strains. Finally, when assessing normality, only strains of Lactobacillus and S. sanguinis showed normal distribution $(p>0.05)$.

3.3. In Vitro Antimicrobial Activity of New "Tumbo" Dentifrice against Commercial Toothpastes. First, when comparing the antimicrobial activity of our new toothpaste based on pulp and tumble skin, no statistically significant differences were found in strains of $S$. mutans, E. faecalis, Actinomyces, S. sanguinis, and S. oralis $(p>0.05)$. However, only a statistically significant difference between the effect of the peel and the pulp was observed in the strains of Lactobacillus and C. albicans. Second, when comparing with commercial herbal dentifrices Dento Herbal ${ }^{\circledR}$, Colgate Herbal $^{\circledR}$, Kolynos Herbal $^{\circledR}$, Sensodyne ${ }^{\circledR}$, and Parodontax ${ }^{\circledR}$, statistically significant differences were found $p \leq 0.001$. Parodontax toothpaste is one of the most active dentrifrices presented together with our experimental dentifrice; however, Sensodyne was the toothpaste that presented the least antimicrobial activity against the seven strains evaluated in this research (Table 4).

\section{Discussion}

Oral diseases are considered a very important community health problem throughout the world. These lesions can be chronic or acute, often requiring not only therapeutic but also preventive treatment. Therefore, the uses of antimicrobial substances for treatment require the use of a drug that has sufficient efficacy at the site of action and that has no side effects [16]. The toothpaste is a mixture of components that are used for cleaning and polishing the teeth. Basically, there are two types of dentifrices, one is simply a preventive dentifrice and the other is therapeutic dentifrice that has certain analgesic, anti-inflammatory, and other components that will help manage certain oral lesions [17]. However, currently, new therapeutic options are being sought in native plants that may offer better clinical benefits in relation to conventional treatments.

Dental products are available in paste, gel, or powder. These are usually applied with a toothbrush to clean the teeth 
TABle 1: Chemical components of experimental dentifrice based on Passiflora mollisima "tumbo."

\begin{tabular}{lcc}
\hline & Components & Properties \\
\hline 1 & Precipitated calcium carbonate & Abrasive \\
2 & Tetrasodium pyrophosphate & Additives \\
3 & AEROSIL (hydrophilic pyrogenic silica) & Additives \\
4 & Colloidal silicon dioxide USP & Preservative \\
5 & NIPAGIN (methylparaben sodium) or methyl & Sweetener \\
6 & parahydroxybenzoate & Flavoring agent \\
7 & Saccharin sodium, powder or crystallized & preparation to homogenize the \\
8 & Menthol mint aroma crystals & Moisturizers are added slowly to \\
9 & Deionized, demineralized, or distilled water & poisturizers are added slowly to homogenize the \\
10 & Glycerin (or glycerol) & Binder \\
11 & Xanthan gum & Whiteness to dentifrices \\
12 & Titanium dioxide (dye) & Surfactants \\
13 & Sodium lauryl sulfate (SLE) & 1450 ppm fluorine \\
14 & Sodium fluoride (fluoride) & Moisturizers
\end{tabular}

TABLE 2: Comparison of the antimicrobial activity of tumbo dentifrice against seven strains of the oral cavity (formulation without fluoride).

\begin{tabular}{|c|c|c|c|c|c|c|}
\hline Microorganisms & Part of the plant & Evaluation time (hours) & Mean \pm SD & Min & Max & $p^{*}$ \\
\hline \multirow{4}{*}{ S. mutans } & \multirow{2}{*}{ Pulp } & 24 & $20.0 \pm 2.1$ & 17.8 & 25.2 & 0.093 \\
\hline & & 48 & $19.3 \pm 1.1$ & 17.6 & 21.1 & 0.479 \\
\hline & \multirow{2}{*}{ Peel } & 24 & $16.0 \pm 1.5$ & 14.6 & 18.6 & 0.008 \\
\hline & & 48 & $15.5 \pm 1.5$ & 13.8 & 18.0 & 0.061 \\
\hline \multirow{4}{*}{ E. faecalis } & \multirow{2}{*}{ Pulp } & 24 & $15.5 \pm 1.1$ & 13.8 & 17.3 & 0.492 \\
\hline & & 48 & $15.2 \pm 1.2$ & 13.0 & 17.0 & 0.999 \\
\hline & \multirow{2}{*}{ Peel } & 24 & $15.5 \pm 0.4$ & 15.0 & 16.5 & 0.647 \\
\hline & & 48 & $15 \pm 0.4$ & 14.3 & 15.8 & 0.988 \\
\hline \multirow{4}{*}{ Actinomyces } & \multirow{2}{*}{ Pulp } & 24 & $18.3 \pm 1$ & 17.3 & 20.2 & 0.012 \\
\hline & & 48 & $23.6 \pm 4.4$ & 17.0 & 29.0 & 0.078 \\
\hline & \multirow{2}{*}{ Peel } & 24 & $18.7 \pm 3.3$ & 16.3 & 29.1 & $p \leq 0.001$ \\
\hline & & 48 & $18.6 \pm 3.3$ & 16.3 & 29.1 & $p \leq 0.001$ \\
\hline \multirow{4}{*}{ Lactobacillus } & \multirow{2}{*}{ Pulp } & 24 & $20.8 \pm 0.6$ & 19.8 & 22.1 & 0.623 \\
\hline & & 48 & $20.2 \pm 0.7$ & 18.9 & 21.5 & 0.491 \\
\hline & \multirow{2}{*}{ Peel } & 24 & $17.6 \pm 0.2$ & 17.2 & 18.1 & 0.842 \\
\hline & & 48 & $17.1 \pm 0.2$ & 16.8 & 17.6 & 0.511 \\
\hline \multirow{4}{*}{ C. albicans } & \multirow{2}{*}{ Pulp } & 24 & $15.5 \pm 0.9$ & 13.8 & 17.1 & 0.730 \\
\hline & & 48 & $24.7 \pm 1.3$ & 23.0 & 27.2 & 0.540 \\
\hline & \multirow{2}{*}{ Peel } & 24 & $19.3 \pm 1.7$ & 16.2 & 22.3 & 0.534 \\
\hline & & 48 & $18.8 \pm 1.8$ & 16.0 & 22.1 & 0.274 \\
\hline \multirow{4}{*}{ S. sanguinis } & \multirow{2}{*}{ Pulp } & 24 & $14.9 \pm 0.1$ & 14.7 & 15.3 & 0.331 \\
\hline & & 48 & $14.1 \pm 0.5$ & 12.9 & 14.9 & 0.555 \\
\hline & \multirow{2}{*}{ Peel } & 24 & $15.9 \pm 0.4$ & 15.3 & 16.6 & 0.447 \\
\hline & & 48 & $15.1 \pm 0.5$ & 14.2 & 16.0 & 0.406 \\
\hline \multirow{4}{*}{ S. oralis } & \multirow{2}{*}{ Pulp } & 24 & $14.5 \pm 0.9$ & 13.6 & 16.4 & 0.016 \\
\hline & & 48 & $14.1 \pm 0.9$ & 13.0 & 16.2 & 0.195 \\
\hline & \multirow{2}{*}{ Peel } & 24 & $16.5 \pm 0.4$ & 15.6 & 17.3 & 0.699 \\
\hline & & 48 & $15.7 \pm 0.6$ & 14.8 & 16.8 & 0.941 \\
\hline
\end{tabular}

All measurements were made in $\mathrm{mm} .{ }^{*}$ Shapiro-Wilk test.

and thus maintain oral hygiene by eliminating the pathogenic microbial flora. Traditionally, toothpastes contain a mild abrasive, detergent, flavoring agent, fluoride, and binder. Other common ingredients include moisturizers, desensitizers, and various medications to prevent various oral pathologies [18, 19]. Toothpaste and mouthwash should contain certain antimicrobial agents that are commonly used as products that improve oral hygiene. Its use goes back to ancient times and continues until now; therefore, there is a need to find new substitutes based on natural products that help prevent diseases of the oral cavity [20]. 
TABLE 3: Comparison of the antimicrobial activity of tumbo dentifrice against seven strains of the oral cavity (formulation with fluoride).

\begin{tabular}{|c|c|c|c|c|c|c|}
\hline Microorganisms & Part of the plant & Evaluation time (hours) & Mean \pm SD & Min & $\operatorname{Max}$ & $p^{*}$ \\
\hline \multirow{4}{*}{ S. mutans } & \multirow{2}{*}{ Pulp } & 24 & $21.0 \pm 1.8$ & 19.2 & 25.6 & 0.029 \\
\hline & & 48 & $19.8 \pm 1.4$ & 17.9 & 22.3 & 0.178 \\
\hline & \multirow{2}{*}{ Peel } & 24 & $14.9 \pm 0.4$ & 13.8 & 15.5 & 0.070 \\
\hline & & 48 & $14.5 \pm 0.4$ & 13.5 & 15.2 & 0.178 \\
\hline \multirow{4}{*}{ E. faecalis } & \multirow{2}{*}{ Pulp } & 24 & $16.3 \pm 3.9$ & 12.9 & 25.3 & $p \leq 0.001$ \\
\hline & & 48 & $13.8 \pm 1.4$ & 11.3 & 15.8 & 0.442 \\
\hline & \multirow{2}{*}{ Peel } & 24 & $14.3 \pm 0.3$ & 13.8 & 14.9 & 0.205 \\
\hline & & 48 & $13.9 \pm 0.5$ & 12.8 & 14.8 & 0.754 \\
\hline \multirow{4}{*}{ Actinomyces } & \multirow{2}{*}{ Pulp } & 24 & $19.0 \pm 0.8$ & 17.8 & 20.2 & 0.838 \\
\hline & & 48 & $22.1 \pm 1.3$ & 19.9 & 24.6 & 0.717 \\
\hline & \multirow{2}{*}{ Peel } & 24 & $18.9 \pm 3.2$ & 17.2 & 29.2 & $p \leq 0.001$ \\
\hline & & 48 & $18.9 \pm 3.2$ & 17.2 & 29.2 & $p \leq 0.001$ \\
\hline \multirow{4}{*}{ Lactobacillus } & \multirow{2}{*}{ Pulp } & 24 & $21.0 \pm 0.3$ & 20.6 & 21.9 & 0.268 \\
\hline & & 48 & $20.3 \pm 0.5$ & 19.6 & 21.2 & 0.795 \\
\hline & \multirow{2}{*}{ Peel } & 24 & $18.1 \pm 0.4$ & 17.5 & 18.9 & 0.704 \\
\hline & & 48 & $17.5 \pm 0.4$ & 16.8 & 18.2 & 0.765 \\
\hline \multirow{4}{*}{ C. albicans } & \multirow{2}{*}{ Pulp } & 24 & $17.4 \pm 1.4$ & 15.7 & 19.7 & 0.155 \\
\hline & & 48 & $21.2 \pm 1.9$ & 17.0 & 23.6 & 0.180 \\
\hline & \multirow{2}{*}{ Peel } & 24 & $21.1 \pm 0.9$ & 20.2 & 22.6 & 0.064 \\
\hline & & 48 & $19.4 \pm 3.1$ & 9.8 & 22.0 & $p \leq 0.001$ \\
\hline \multirow{4}{*}{ S. sanguinis } & \multirow{2}{*}{ Pulp } & 24 & $15.3 \pm 0.3$ & 15.0 & 16.0 & 0.205 \\
\hline & & 48 & $14.0 \pm 0.3$ & 13.7 & 14.9 & 0.057 \\
\hline & \multirow{2}{*}{ Peel } & 24 & $15.5 \pm 0.5$ & 14.9 & 16.5 & 0.084 \\
\hline & & 48 & $14.8 \pm 0.5$ & 14.0 & 16.2 & 0.126 \\
\hline \multirow{4}{*}{ S. oralis } & \multirow{2}{*}{ Pulp } & 24 & $14.4 \pm 0.4$ & 13.6 & 15.0 & 0.625 \\
\hline & & 48 & $14.3 \pm 0.7$ & 12.9 & 15.5 & 0.932 \\
\hline & \multirow{2}{*}{ Peel } & 24 & $17.0 \pm 0.4$ & 16.5 & 17.7 & 0.165 \\
\hline & & 48 & $16.4 \pm 0.5$ & 15.6 & 17.0 & 0.029 \\
\hline
\end{tabular}

All measurements were made in mm. *Shapiro-Wilk test.

There is little literature that evaluated the antibacterial properties of Passiflora mollissima in its dentifrice form; however, some close studies are consistent with the results of the present study. Although they focus more on evaluating the physical-chemical properties, they conclude that the average abrasivity of formulations with hydrated silica is more than that of formulations with dicalcium phosphate. In addition, a study on 26 commercial toothpastes indicated that the roughness of toothpastes with hydrated silica abrasive was significantly different from that of the toothpaste containing calcium phosphate [21].

On the contrary, some research studies that have studied the antimicrobial effect of new formulations of herbal toothpastes with other different plants to Passiflora mollissima (tumbo) mentioned that the antibacterial activity of the dental gel was carried out by the disc diffusion method Assessing its effectiveness against Gram-negative bacteria such as Pseudomonas aeruginosa and E. coli and Grampositive bacteria such as Staphylococcus aureus incubated for 24 hours at $37^{\circ} \mathrm{C}$. When contrasting, these results were similar with our study because we also found a great antimicrobial activity against Gram-positive and Gram-negative germs [17-24].

In the present investigation, comparatively equal and better results have been observed with formulations manufactured in the laboratory that are commercialized daily. Both preparations have shown equal efficacy in terms of antimicrobial activity, capacity, and $\mathrm{pH}$. The comparison of this activity of the marketing pastes with the formulations made in the laboratory suggests that the formulations made in laboratories have a higher sensitivity than the pastes sold. Also, they mention a significant result for cleaning capacity, saying that it is similar to the results obtained in commercial formulations [20-25].

Some investigations describe that toothpastes should have good consistency and smooth texture without signs of deterioration, such as phase separation, gasification, and fermentation, when all samples are placed at a temperature of $45 \pm 20^{\circ} \mathrm{C}$ for a period of 28 days. This confirms that all experimental toothpastes have good stability [4]. There is no literature on formulation of toothpastes of this natural resource; however, when contrasting the methodology of the formulation of the herbal toothpaste, it was found that some studies were done based on the leaves of neem and guava and the bark of cinnamon and that in the formulation testing phase, there are classic problems such as lack of homogeneity, spreadability, and foamability. But, that research showed that herbal toothpaste was greenish brown and showed good homogeneity with absence of bulk and good antimicrobial activity similar to our proposal based on Passiflora mollissima [22].

On the contrary, the oral microorganisms that generally produce lactic acid eliminate the mineral materials of the dental enamel leading to the formation of caries and also to 
TABLE 4: Comparison of the antimicrobial activity of tumbo dentifrice against different commercial toothpastes.

\begin{tabular}{|c|c|c|c|c|c|c|c|}
\hline Microorganisms & Groups & Mean \pm SD & Min & Max & $p^{*}$ & $p$ & $p$ \\
\hline \multirow{7}{*}{ S. mutans } & Pulp & $20.0 \pm 2.1$ & 17.8 & 25.2 & 0.093 & $0.651^{++}$ & \multirow{7}{*}{$p \leq 0.001^{\dagger}$} \\
\hline & Peel & $16.0 \pm 1.5$ & 14.6 & 18.6 & 0.008 & & \\
\hline & Dento Herbal ${ }^{\circledR}$ & $17.0 \pm 0.6$ & 16.2 & 17.8 & 0.734 & \multirow{5}{*}{$p \leq 0.001$} & \\
\hline & Colgate Herbal ${ }^{\circledR}$ & $16.9 \pm 0.8$ & 16.1 & 17.8 & 0.386 & & \\
\hline & Kolynos Herbal ${ }^{\circledR}$ & $15.1 \pm 0.2$ & 14.9 & 15.5 & 0.392 & & \\
\hline & Sensodyne ${ }^{\circledR}$ & $11.2 \pm 0.8$ & 10.0 & 12.0 & 0.191 & & \\
\hline & Parodontax ${ }^{\circledR}$ & $30.2 \pm 1.5$ & 28.9 & 32.5 & 0.194 & & \\
\hline \multirow{7}{*}{ E. faecalis } & Pulp & $15.5 \pm 1.1$ & 13.8 & 17.3 & 0.492 & $0.906^{+}$ & \multirow{7}{*}{$p \leq 0.001^{* *}$} \\
\hline & Peel & $15.5 \pm 0.4$ & 15.0 & 16.5 & 0.647 & & \\
\hline & Dento Herbal ${ }^{\circledR}$ & $12.8 \pm 0.4$ & 12.3 & 13.2 & 0.303 & & \\
\hline & Colgate Herbal ${ }^{\circledR}$ & $13.9 \pm 0.8$ & 12.9 & 14.9 & 0.900 & & \\
\hline & Kolynos Herbal ${ }^{\circledR}$ & $14.2 \pm 0.6$ & 13.5 & 14.9 & 0.513 & $p \leq 0.001$ & \\
\hline & Sensodyne ${ }^{\circledR}$ & $10.6 \pm 0.3$ & 10.2 & 11.0 & 0.408 & & \\
\hline & Parodontax ${ }^{\circledR}$ & $15.7 \pm 0.2$ & 15.5 & 16.1 & 0.649 & & \\
\hline \multirow{7}{*}{ Actinomyces } & Pulp & $18.3 \pm 1$ & 17.3 & 20.2 & 0.012 & $0.143^{++}$ & \multirow{7}{*}{$p \leq 0.001^{\dagger}$} \\
\hline & Peel & $18.7 \pm 3.3$ & 16.3 & 29.1 & 0.000 & & \\
\hline & Dento Herbal ${ }^{\circledR}$ & $14.1 \pm 0.4$ & 13.8 & 14.7 & 0.303 & & \\
\hline & Colgate Herbal ${ }^{\circledR}$ & $15 \pm 0.1$ & 14.8 & 15.2 & 0.714 & & \\
\hline & Kolynos Herbal ${ }^{\circledR}$ & $13.4 \pm 0.1$ & 13.2 & 13.6 & 0.000 & $p \leq 0.001$ & \\
\hline & Sensodyne ${ }^{\circledR}$ & $13.2 \pm 0.2$ & 12.9 & 13.5 & 0.000 & & \\
\hline & Parodontax ${ }^{\circledR}$ & $14.1 \pm 0.5$ & 13.5 & 14.9 & 0.889 & & \\
\hline \multirow{7}{*}{ Lactobacillus } & Pulp & $20.8 \pm 0.6$ & 19.8 & 22.1 & 0.623 & $p \leq 0.001^{+}$ & \multirow{7}{*}{$p \leq 0.001^{* *}$} \\
\hline & Peel & $17.6 \pm 0.2$ & 17.2 & 18.1 & 0.842 & & \\
\hline & Dento Herbal ${ }^{\circledR}$ & $17.7 \pm 0.6$ & 17.0 & 18.3 & 0.443 & & \\
\hline & Colgate Herbal ${ }^{\circledR}$ & $21.2 \pm 0.9$ & 20.1 & 22.3 & 0.997 & & \\
\hline & Kolynos Herbal ${ }^{\circledR}$ & $22.1 \pm 0.8$ & 20.9 & 23.0 & 0.696 & $p \leq 0.001$ & \\
\hline & Sensodyne ${ }^{\circledR}$ & $15.5 \pm 2.8$ & 12.9 & 18.3 & 0.126 & & \\
\hline & Parodontax ${ }^{\circledR}$ & $15.2 \pm 0.2$ & 14.9 & 15.5 & 0.910 & & \\
\hline \multirow{7}{*}{ C. albicans } & Pulp & $17.4 \pm 1.4$ & 15.7 & 19.7 & 0.730 & $p \leq 0.001^{+}$ & \multirow{7}{*}{$p \leq 0.001^{\dagger}$} \\
\hline & Peel & $21.1 \pm 0.9$ & 20.2 & 22.6 & 0.534 & \multirow{6}{*}{$p \leq 0.001$} & \\
\hline & Dento Herbal ${ }^{\circledR}$ & $17.9 \pm 0.6$ & 17.3 & 18.7 & 0.513 & & \\
\hline & Colgate Herbal ${ }^{\circledR}$ & $21.7 \pm 0.4$ & 21.2 & 22.3 & 0.970 & & \\
\hline & Kolynos Herbal ${ }^{\circledR}$ & $20.9 \pm 1.5$ & 19.9 & 23.2 & 0.025 & & \\
\hline & Sensodyne ${ }^{\circledR}$ & 0 & 0 & 0 & - & & \\
\hline & Parodontax ${ }^{\circledR}$ & $24.4 \pm 0.6$ & 23.8 & 25.0 & 0.111 & & \\
\hline \multirow{7}{*}{ S. sanguinis } & Pulp & $14.9 \pm 0.1$ & 14.7 & 15.3 & 0.331 & $1.000^{+}$ & \multirow{7}{*}{$p \leq 0.001^{* *}$} \\
\hline & Peel & $15.9 \pm 0.4$ & 15.3 & 16.6 & 0.447 & & \\
\hline & Dento Herbal ${ }^{\circledR}$ & $19.7 \pm 0.5$ & 19.0 & 20.2 & 0.369 & & \\
\hline & Colgate Herbal ${ }^{\circledR}$ & $21.1 \pm 0.5$ & 20.4 & 21.8 & 0.994 & & \\
\hline & Kolynos Herbal ${ }^{\circledR}$ & $20.4 \pm 1.1$ & 19.6 & 22.1 & 0.211 & $p \leq 0.001$ & \\
\hline & Sensodyne ${ }^{\circledR}$ & 0 & 0 & 0 & - & & \\
\hline & Parodontax ${ }^{\circledR}$ & $26.1 \pm 0.5$ & 25.6 & 26.9 & 0.680 & & \\
\hline \multirow{7}{*}{ S. oralis } & Pulp & $14.5 \pm 0.9$ & 13.6 & 16.4 & 0.016 & $0.425^{++}$ & \multirow{7}{*}{$p \leq 0.001^{\dagger}$} \\
\hline & Peel & $16.5 \pm 0.4$ & 15.6 & 17.3 & 0.699 & & \\
\hline & Dento Herbal ${ }^{\circledR}$ & $16 \pm 0.6$ & 15.2 & 16.8 & 0.999 & & \\
\hline & Colgate Herbal ${ }^{\circledR}$ & $15.6 \pm 0.5$ & 15.1 & 16.3 & 0.688 & & \\
\hline & Kolynos Herbal ${ }^{\circledR}$ & $19.9 \pm 0.1$ & 19.8 & 20.2 & 0.849 & $p \leq 0.001$ & \\
\hline & Sensodyne ${ }^{\circledR}$ & 0 & 0 & 0 & - & & \\
\hline & Parodontax ${ }^{\circledR}$ & $17.7 \pm 0.4$ & 17.2 & 18.2 & 0.420 & & \\
\hline
\end{tabular}

All measurements were made in $\mathrm{mm}$. The concentrations were calculated from the dilutions of the active ingredient; the Sensodyne control group was excluded from any statistical analysis because the antimicrobial activity was not present. ${ }^{*}$ Shapiro-Wilk test. ${ }^{+}$Student $t$-test. ${ }^{++}$Mann-Whitney $U$ test. ${ }^{* *}$ ANOVA test. ${ }^{\dagger}$ Kruskal-Wallis test. Level of significance $p<0.05$.

the development of infections in the lower layers of the tooth. Although damage and decomposition is a complicated multifactorial disease, the patient's oral hygiene rate is one of the most important factors in the decomposition process. If optimal oral hygiene is provided, there will be no bacterial plaque [23]. Hence, the addition of fluoride in toothpastes reduces tooth decay, so one of the main objectives of this research was to demonstrate the antimicrobial efficacy of the experimental toothpaste based on Passiflora mollisima with and without the addition of fluoride anion to verify if this chemical compound promotes a synergism in its antimicrobial effectiveness [24]. 
Our results showed that the dentifrice based on "tumbo" had an antimicrobial activity against $S$. mutans $21.0 \pm 1.8 \mathrm{~mm}$, E. faecalis $16.3 \pm 3.9 \mathrm{~mm}$, Actinomyces $22.1 \pm 1.3 \mathrm{~mm}$, and Lactobacillus $21.0 \pm 1.3 \mathrm{~mm}$; this coincided with the results described by Dave et al. who found an area of inhibition of herbal toothpaste based on Eugenia caryophyllus, Acacia nilotica, and Mimusops elengi against S. aureus and E. coli. Another study with which we agreed was that carried out by Ghelichli who mentioned that the herbal toothpaste "Salvadora" had antibacterial properties against the oral microbial flora is due to the alkaloids present in the stem of the plant "Salvadora." Although the natural resources were different from the Passiflora mollissima used in the present study, it is evident that the plants have a great antimicrobial potential against different oral microorganisms [25-27].

The main limitations of this research were as follows: One of the main limitations was the availability of oral microorganisms, because these strains had to be imported from the USA, which demanded a delay in the microbiological tests. Another important limitation was the limited available evidence that evaluated or created an experimental toothpaste based on Passiflora mollissima, which made it difficult to analyze and contrast the promising results obtained in this research.

Finally, the present investigation was of social importance given that the patients will probably benefit from demonstrating the antimicrobial effectiveness of this new toothpaste based on Passiflora mollissima "tumbo" which is consumed very frequently in the high Andean areas of Peru. On the contrary, it had a theoretical importance because there is scarce literature that has evaluated the therapeutic properties of this natural resource in relation to its use in the stomatology. Finally, it had methodological importance because a new chemical formulation was proposed for the development of this new dentifrice based on "tumbo" which represents a milestone in the Peruvian stomatology that always seeks to use new active ingredients that help prevent and treat certain oral diseases.

\section{Conclusions}

The experimental dentifrice based on the pulp of Passiflora mollissima showed to have the greatest antimicrobial effect in comparison with the dentifrice based on the peel, although some antimicrobial strains such as Actinomyces, C. albicans, $S$. sanguinis, and $S$. oralis were more susceptible to the dentifrice based on the peel. Finally, according to our results, it is concluded that in relation to antimicrobial comparisons with commercial toothpastes, our dental proposal is equal to or superior to the effectiveness of these, which opens a great line of research in relation to this Peruvian natural resource (tumbo).

\section{Data Availability}

The data used to support the findings of this study are available from the corresponding author upon request.

\section{Conflicts of Interest}

The authors declare that there are no conflicts of interest.

\section{Acknowledgments}

The research was supported by the Universidad Privada San Juan Bautista with the resolution of the Vice-Rectorate for research no. 003-2018-VRI-UPSJB. We wish to thank the Universidad Privada San Juan Bautista for the financial support to execute the present investigation and the Herbarium of the Natural History Museum of the Universidad Nacional Mayor de San Marcos (UNMSM).

\section{References}

[1] R. Davies, C. Scully, and A. J. Preston, "Dentifrices-an update," Medicina Oral, Patología Oral y Cirugía Bucal, vol. 15, no. 6, pp. 976-982, 2010.

[2] M. Ersoy, J. Tanalp, E. Ozel, R. Cengizlier, and M. Soyman, "The allergy of toothpaste: a case report," Allergologia et Immunopathologia, vol. 36, no. 6, pp. 368-370, 2008.

[3] J. J. Jardim, L. S. Alves, and M. Maltz, "The history and global market of oral home-care products," Brazilian Oral Research, vol. 23, no. 1, pp. 17-22, 2009.

[4] T. Mangilal and M. Ravikumar, "Preparation and evaluation of herbal toothpaste and compared with commercial herbal toothpastes: an in vitro study," International Journal of Ayurvedic and Herbal Medicine, vol. 6, no. 3, pp. 2251-2266, 2016.

[5] J. Moran, M. Addy, R. G. Newcombe, and I. Marlow, "A study to assess the plaque inhibitory action of a newly formulated triclosan toothpaste," Journal of Clinical Periodontology, vol. 28, no. 1, pp. 86-89, 2001.

[6] J. Okpalugo, K. Ibrahim, and U. S. Inyang, "Toothpaste formulation efficacy in reducing oral flora," Tropical Journal of Pharmaceutical Research, vol. 8, no. 1, pp. 71-77, 2009.

[7] R. E. Alves, E. S. de Brito, M. S. M. Rufino, and C. G. Sampaio, "Antioxidant activity measurement in tropical fruits: a case study with acerola," Acta Horticulturae, no. 773, pp. 299-305, 2008.

[8] M. D. S. M. Rufino, R. E. Alves, E. S. de Brito, J. Pérez-Jiménez, F. Saura-Calixto, and J. Mancini-Filho, "Bioactive compounds and antioxidant capacities of 18 non-traditional tropical fruits from Brazil," Food Chemistry, vol. 121, no. 4, pp. 996-1002, 2010.

[9] E. O. Baldeón, M. Alcañiz, R. Masot, E. M. Fuentes, J. M. Barat, and R. Grau, "Voltammetry pulse array developed to determine the antioxidant activity of camu-camu (Myrciaria dubia (H.B.K.) McVaug) and tumbo (Passiflora mollissima (Kunth) L.H. Bailey) juices employing voltammetric electronic tongues," Food Control, vol. 54, pp. 181-187, 2015.

[10] P. Leterme, A. Buldgen, F. Estrada, and A. M. Londoño, "Mineral content of tropical fruits and unconventional foods of the Andes and the rain forest of Colombia," Food Chemistry, vol. 95, no. 4, pp. 644-652, 2006.

[11] J. Contreras-Calderón, L. Calderón-Jaimes, E. GuerraHernández, and B. García-Villanova, "Antioxidant capacity, phenolic content and vitamin C in pulp, peel and seed from 24 exotic fruits from Colombia," Food Research International, vol. 44, no. 7, pp. 2047-2053, 2011.

[12] S. M. Zucolotto, C. Fagundes, F. H. Reginatto et al., "Analysis of C-glycosyl flavonoids from South American Passiflora species by HPLC-DAD and HPLC-MS," Phytochemical Analysis, vol. 23, no. 3, pp. 232-239, 2012.

[13] M. Botero, S. Ricaurte, C. Monsalve, and B. Rojano, "Capacidad reductora de 15 frutas tropicales," Scientia et Technica, vol. 33, pp. 295-296, 2007. 
[14] D. Medina-Flores, G. Ulloa-Urizar, R. Camere-Colarossi, S. Caballero-García, F. Mayta-Tovalino, and J. del ValleMendoza, "Antibacterial activity of Bixa orellana L. (achiote) against Streptococcus mutans and Streptococcus sanguinis," Asian Pacific Journal of Tropical Biomedicine, vol. 6, no. 5, pp. 400-403, 2016.

[15] R. Camere-Colarossi, G. Ulloa-Urizar, D. Medina-Flores, S. Caballero-García, F. Mayta-Tovalino, and J. del ValleMendoza, "Antibacterial activity of Myrciaria dubia (Camu camu) against Streptococcus mutans and Streptococcus sanguinis," Asian Pacific Journal of Tropical Biomedicine, vol. 6, no. 9, pp. 740-744, 2016.

[16] A. Katiyar, S. K. Prajapati, A. Akhtar, G. Ambarish, and S. Vishwakarma, "Therapeutic strategies for the treatment of periodontitis," International Resarch Journal of Pharmacy, vol. 3, no. 8, pp. 61-66, 2012.

[17] J. B. Wilkinson and R. J. Moore, Harry's Cosmeticology, Chemical Publishing, New York, NY, USA, 7th edition, 1982.

[18] B. M. Mithal and R. N. Saha, A Handbook of Cosmetics, Vallabh Prakashan, Delhi, India, 2nd edition, 2006.

[19] H. Mridul, A. Kumar, S. K. Maurya1, and A. Seth, "Formulation development, physico-chemical characterization and evaluation of anti-microbial activity of herbal tooth gel," Journal of Chemical and Pharmaceutical Research, vol. 6, no. 3, pp. 1279-1285, 2014.

[20] T. Namba, M. Tsunezuka, and M. Hattori, "Dental caries prevention by traditional chinese medicines," Planta Medica, vol. 44, no. 2, pp. 100-106, 1982.

[21] B. R. Schemehorn, M. H. Moore, and M. S. Putt, "Abrasion, polishing, and stain removal characteristics of various commercial dentifrices in vitro," Journal of Clinical Dentistry, vol. 22, no. 1, pp. 11-18, 2011.

[22] D. Pavan, R. Roshan, and G. Mahendra, "Formulation and evaluation of herbal toothpaste: compared with marketed preparation," International Journal of Pharmaceutics \& Drug Analysis, vol. 5, no. 10, pp. 406-410, 2017.

[23] I. Kleinberg, "A Mixed-bacteria ecological approach to understanding the role of the oral bacteria in dental caries causation: an alternative to Streptococcus mutans and the specific-plaque hypothesis," Critical Reviews in Oral Biology \& Medicine, vol. 13, no. 2, pp. 108-125, 2002.

[24] S. R. Parwani, R. N. Parwani, P. J. Chitnis, H. P. Dadlani, and S. V. S. Prasad, "Comparative evaluation of anti-plaque efficacy of herbal and $0.2 \%$ chlorhexidine gluconate mouthwash in a 4-day plaque re-growth study," Journal of Indian Society of Periodontology, vol. 17, no. 1, pp. 72-77, 2013.

[25] M. Ghelichli, "Formulation of new herbal salvadora toothpaste with anti decay, wound healing and caring tooth and periodontal diseases," Bulletin of Environment, Pharmacology and Life Sciences, vol. 3, no. 11, pp. 115-122, 2014.

[26] K. Dave, L. Panchal, and P. Shelat, "Development and evaluation of antibacterial herbal toothpaste containing Eugenia caryophullus, Acacia nilotica and Mimusops elengi," International Journal of Chemistry and Pharmaceutical Sciences, vol. 2, no. 3, pp. 666-675, 2014.

[27] A. Calderon, J. Salas, G. Dapello et al., "Assessment of antibacterial and antifungal properties and in vivo cytotoxicity of peruvian Passiflora mollissima," Journal of Contemporary Dental Practice, vol. 20, no. 2, pp. 145-151, 2019. 


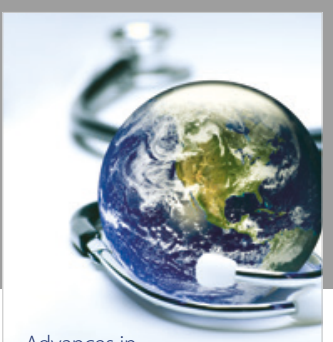

Advances in
Public Health

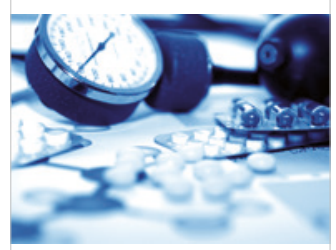

Case Reports in

Medicine

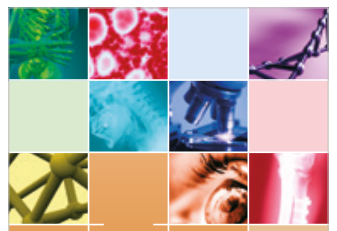

niernational Journal of

Biomaterials
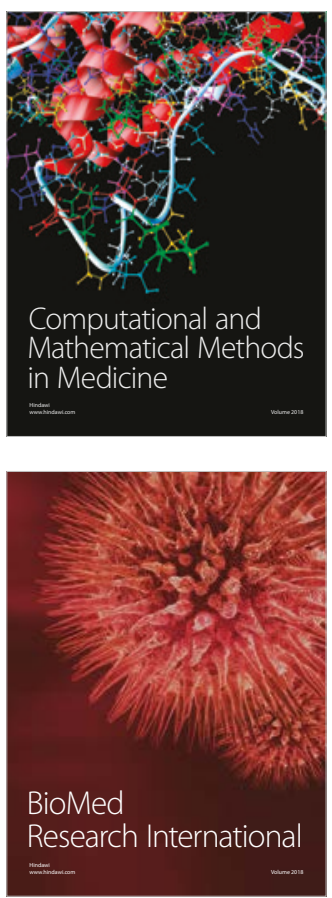

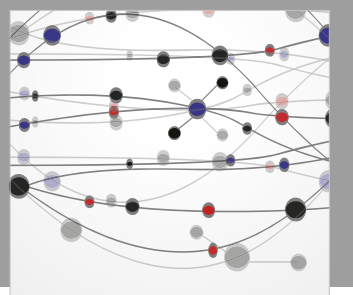

The Scientific World Journal Dentistry

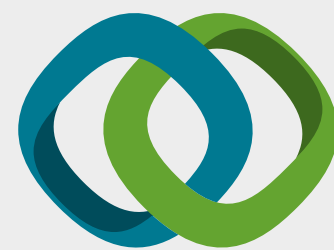

Hindawi

Submit your manuscripts at

www.hindawi.com
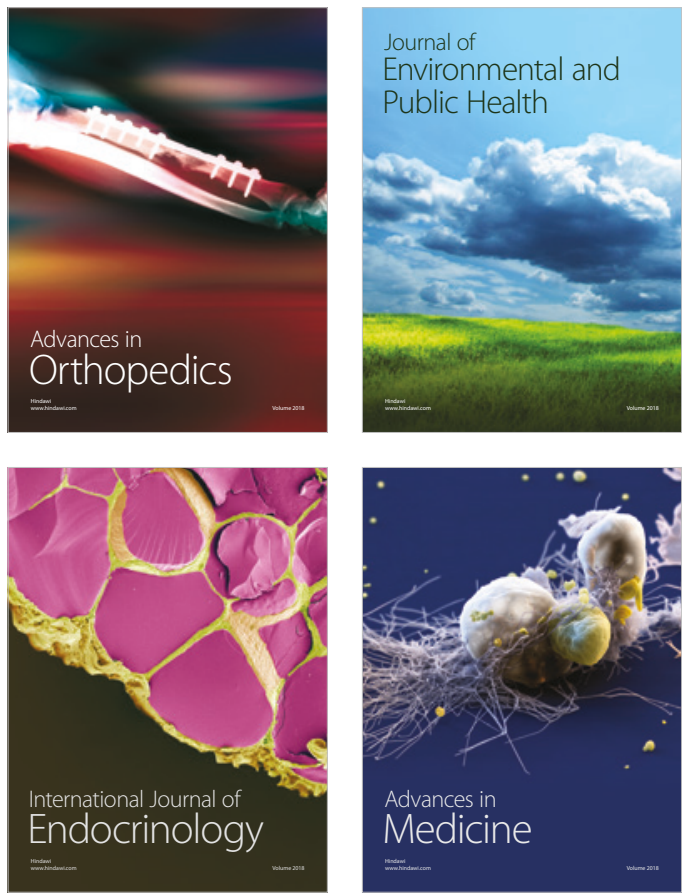
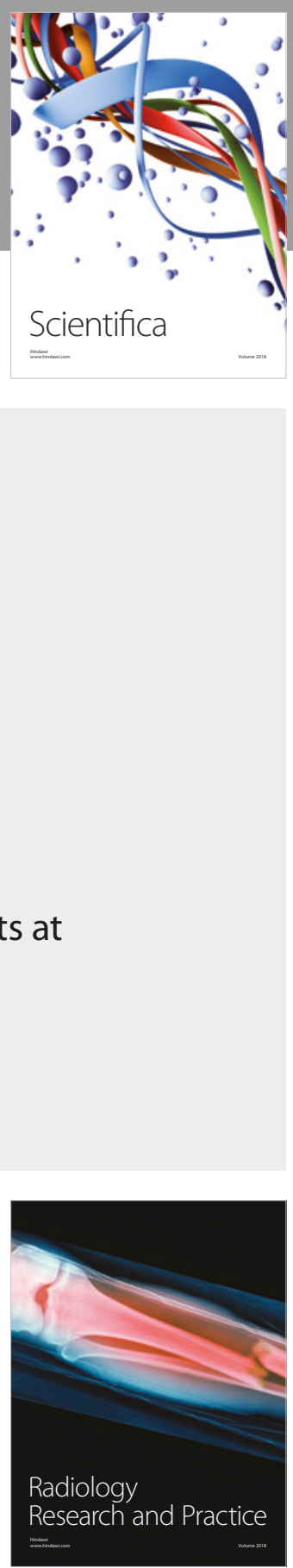

Scientifica

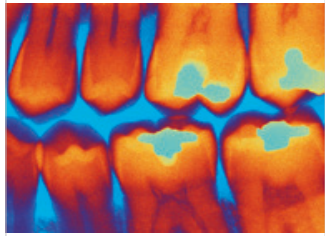

Case Reports in

Dentistry
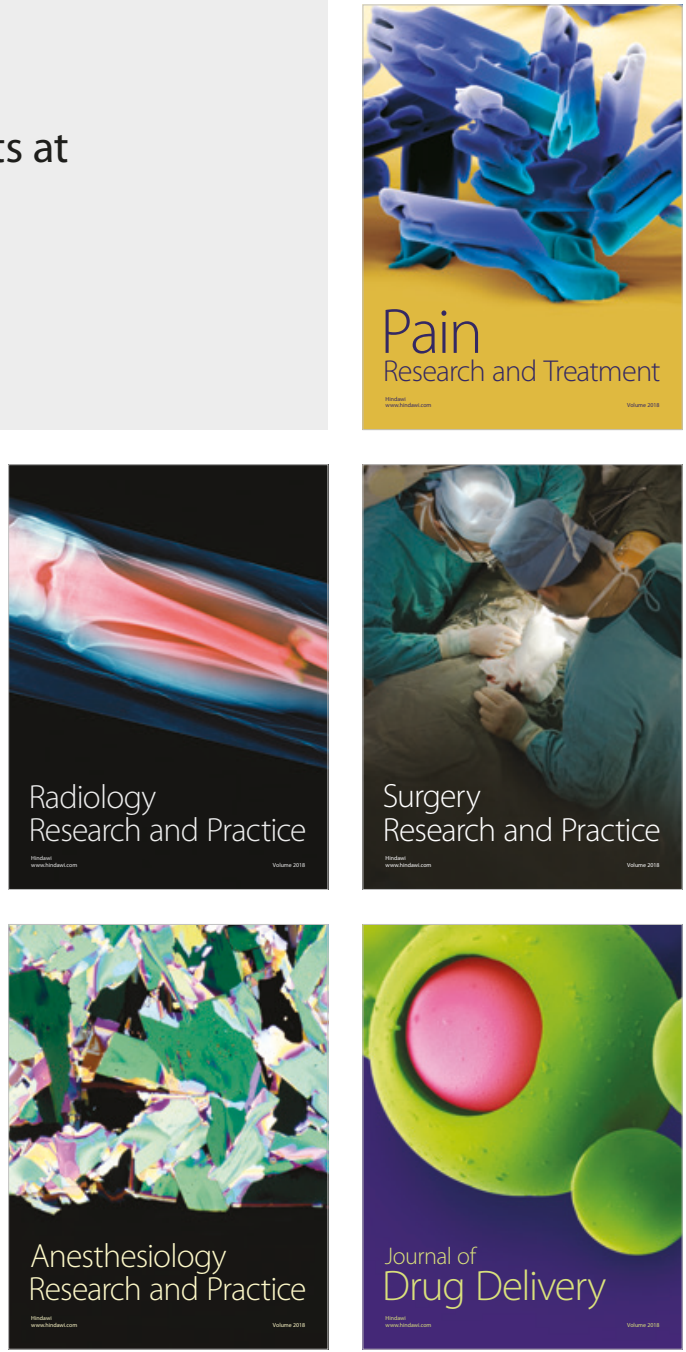